\title{
The relationship between tumour T-lymphocyte infiltration, the systemic inflammatory response and survival in patients undergoing curative resection for colorectal cancer
}

\author{
K Canna', PA McArdle', DC McMillan ${ }^{*, 1}$, A-M McNicol' ${ }^{2}$, GW Smith ${ }^{2}$, RF McKee' and CS McArdle' \\ 'University Department of Surgery, Royal Infirmary, Glasgow G3I 2ER, UK; ${ }^{2}$ Department of Pathology, Royal Infirmary, Glasgow G3I 2ER, UK
}

There is increasing evidence that both local and systemic inflammatory responses play an important role in the progression of a variety of common solid tumours. The aim of the present study was to examine the relationship between tumour T-lymphocyte subset infiltration, the systemic inflammatory response and cancer-specific survival in patients with colorectal cancer. In all, I47 patients undergoing potentially curative resection for colorectal cancer were studied. Circulating concentrations of $C$-reactive protein were measured prior to surgery. CD4 + and CD8 + T-lymphocyte infiltration of the tumour was assessed using immunohistochemistry and a point counting technique. When patients were grouped according to the percentage tumour volume of CD4 + T-lymphocytes, there was no difference in terms of age, sex, tumour site, stage and tumour characteristics. However, there was an inverse relationship between percentage tumour CD4 + T-lymphocytes and C-reactive protein $(P<0.01)$. On univariate analysis, both $C$-reactive protein concentrations $(P<0.001)$ and percentage tumour volume of CD4 $+(P<0.05) \mathrm{T}$-lymphocytes were associated with cancer-specific survival. The results of the present study show that low tumour CD4 + T-lymphocyte infiltration is associated with elevated C-reactive protein concentrations and both predict poor cancer-specific survival.

British Journal of Cancer (2005) 92, 65I-654. doi:I0.1038/sj.bjc.66024I9 www.bjcancer.com

Published online 8 February 2005

(c) 2005 Cancer Research UK

Keywords: colorectal cancer; CD4 + and CD8 + T-lymphocytes; C-reactive protein; survival

It has long been recognised that disease progression in cancer patients is not solely determined by the characteristics of the tumour but also by the host response. Indeed, there is increasing evidence that both local and systemic inflammatory responses play an important role in the progression of a variety of common solid tumours (O'Byrne and Dalgleish, 2001; Vakkila and Lotze, 2004).

In patients with colorectal cancer, there is good evidence that, on simple staining of tumour sections, the presence of a pronounced lymphocytic infiltration within the tumour is associated with improved survival (Jass et al, 1987; Ropponen et al, 1997; Nielsen et al, 1999). More recently, the ability to identify lymphocyte subsets by immunohistochemistry has led to renewed interest in the relationship between the tumour inflammatory infiltrate and outcome. Indeed, increased infiltration of the tumour by CD8 + (Naito et al, 1998) and CD4 + T-lymphocytes (Ali et al, 2004) has been shown to be associated with increased survival in patients with colorectal cancer.

There is also increasing evidence that the presence of a systemic inflammatory response, as evidenced by elevated circulating concentrations of C-reactive protein, is associated with early

\footnotetext{
*Correspondence: Dr DC McMillan;

E-mail: d.c.mcmillan@clinmed.gla.ac.uk

Received 25 October 2004; revised 23 December 2004; accepted 4 January 2005; published online 8 February 2005
}

recurrence and poorer survival in patients undergoing potentially curative resection for colorectal cancer (McMillan et al, 1995, 2003; Nielsen et al, 2000).

To date, the inter-relationships between the local and systemic inflammatory responses and outcome does not appear to have been examined in patients with colorectal cancer. The aim of the present study was therefore to examine the relationship between tumour T-lymphocyte subset infiltration, circulating concentrations of C-reactive protein and cancer-specific survival in patients who had undergone potentially curative resection for colorectal cancer.

\section{PATIENTS AND METHODS}

\section{Patients}

Patients with histologically proven colorectal cancer who, on the basis of preoperative imaging and the surgeons' assessment at operation, were considered to have undergone potentially curative resection for Dukes' B and C colorectal cancer between January 1997 and August 2001 in a single surgical unit at Glasgow Royal Infirmary were included in the study. A blood sample was taken prior to surgery for the measurement of C-reactive protein. The tumours were staged using conventional Dukes' classification (Dukes and Bussey, 1958). All patients were followed up at a specialist colorectal cancer clinic. 
C-reactive protein concentrations were measured by a fluorescence polarisation immunoassay and using an Abbott TDXTM analyser and Abbott reagents (Abbott Laboratories, Abbott Park, IL, USA). The limit of detection of the assay is a CRP concentration lower than $5 \mathrm{mgl}^{-1}$. The coefficient of variation, over the range of measurement, was less than $5 \%$, as established by routine quality control procedures. Based on previous work, a C-reactive protein concentration of greater than $10 \mathrm{mgl}^{-1}$ was considered to indicate the presence of a systemic inflammatory response (O'Gorman et al, 2000).

The study was approved by the local ethics committee.

\section{Immunohistochemistry}

Blocks from the primary tumour were fixed in $10 \%$ buffered formalin and embedded in paraffin wax. One representative block of tumour was selected for each patient. Sections $(4 \mu \mathrm{m})$ were cut and mounted on slides coated with aminopropyltriethoxysilane. Sections were then immunostained using the peroxidase-based Envision (Dako, Cambridgeshire, UK) technique as described previously (Bromwich et al, 2003). The primary antibody for CD4 was mouse monoclonal (Vector, Peterborough, UK) and that for CD8 was mouse monoclonal (Dako, Cambridgeshire, UK).

\section{Morphometry}

Quantitative analysis of the lymphoid infiltrate was performed using point counting (Anderson and Dunnill, 1965) with a random sampling technique. With this method, the volume occupied by any given component (volume density) is expressed as a percentage of the total volume of the tissue. A 100-point ocular grid was used at $400 \times$ magnification and 30 fields were counted per case for CD4 + and CD8 + immunopositive cells. Only fields within the tumour (including cancer cell nests and surrounding tissue stroma) were counted. Any normal tissue on the slide was excluded from the analysis.

This final method was designed on the basis of a pilot study, which demonstrated that the volume density of CD4 + and CD8 + of two observers reached a plateau after 25-30 fields. This pilot study also demonstrated that $\mathrm{CD} 4+$ and $\mathrm{CD} 8+$ counts were equivalent to the $\mathrm{CD} 3+$ counts (unpublished data). The observers (Canna and McArdle) were blinded to the clinical outcome of the patient.

\section{Statistics}

Data are presented as median and range. Where appropriate, comparison of patient groups of patients was carried out using contingency table analysis $\left(\chi^{2}\right)$ and the Kruskal-Wallis test for analysis of variance. For the purpose of analysis, T-lymphocyte subsets were grouped by tertiles as described previously (Nielsen et al, 1999). Survival analysis was performed using the Cox proportional-hazard model. Deaths up to 31st March 2004 have been included in the analysis. Analysis was performed using SPSS software (SPSS Inc., Chicago, IL, USA).

\section{RESULTS}

The baseline clinicopathological characteristics of the patients ( $n=147)$ who underwent potentially curative resection for colorectal cancer are shown in Table 1 . The majority were over the age of 65years and had Dukes' stage B tumours. In all, 53 (36\%) patients had an elevated C-reactive protein concentration prior to surgery.

Patients grouped according to tertiles of the percentage tumour volume of CD4 + T-lymphocytes are shown in Table 2 . The tertiles

Table I Clinicopathological characteristics in patients undergoing potentially curative resection for colorectal cancer

\begin{tabular}{lc}
\hline & Patients $(\mathbf{n}=\mathbf{1 4 7})$ \\
\hline Age group (years) $(<65 / 65-74 / \geqslant 75)$ & $46 / 44 / 57$ \\
Sex (male/female) & $78 / 69$ \\
Site (colon/rectum) & $105 / 42$ \\
Dukes' stage $(\mathrm{B} / \mathrm{C})$ & $91 / 56$ \\
C-reactive protein $\left(\leqslant \mid 0 />10 \mathrm{mg}^{-1}\right)$ & $94 / 53$ \\
& \\
Tumour characteristics & \\
Diameter (mm) & $40(10-130)$ \\
Ulceration (no/yes) & $72 / 75$ \\
Differentiation (well/moderate/poor) & $18 / 116 / 13$ \\
Lymphatic invasion (negative/positive) & $124 / 22$ \\
Venous invasion (negative/positive) & $118 / 28$ \\
& \\
\% Tumour volume & \\
CD4+ T-lymphocytes & $0.90(0.03-3.57)$ \\
CD8+ T-lymphocytes & $1.13(0.23-6.30)$ \\
CD4+ plus CD8+ T-lymphocytes & $2.17(0.50-8.27)$ \\
& $116 / 31$ \\
Adjuvant therapy (no/yes) & $92 / 55$ \\
Alive/dead & $39 / 16$ \\
Cancer-specific/intercurrent disease & \\
\hline
\end{tabular}

Table 2 Relationship between increasing percentage volume of CD4+ T-lymphocytes and tumour characteristics in patients undergoing potentially curative resection for colorectal cancer

\begin{tabular}{|c|c|c|c|c|}
\hline & \multicolumn{4}{|c|}{ Percentage volume of CD4+ T-lymphocytes } \\
\hline & Tertile $(n=49)$ & Tertile $(n=49)$ & Tertile $(n=49)$ & $P$-value \\
\hline Sex (male/female) & $22 / 27$ & $24 / 25$ & $32 / 17$ & 0.101 \\
\hline Site (colon/rectum) & $35 / 14$ & $36 / 13$ & $34 / 15$ & 0.905 \\
\hline Dukes' stage $(B / C)$ & $30 / 19$ & $33 / 16$ & $28 / 21$ & 0.578 \\
\hline C-reactive protein $\left(\leqslant 10 />10 \mathrm{mg}^{-1}\right)$ & $22 / 27$ & $32 / 17$ & $39 / 10$ & 0.002 \\
\hline Diameter (tertiles) & $15 / 17 / 17$ & $|6 / 12 / 2|$ & $|8 / 20 /| \mid$ & 0.250 \\
\hline Ulceration (no/yes) & $21 / 28$ & $22 / 27$ & $29 / 20$ & 0.212 \\
\hline Differentiation (well/moderate/poor) & $6 / 38 / 5$ & $7 / 37 / 5$ & $5 / 4 \mid / 3$ & 0.883 \\
\hline Lymphatic invasion (negative/positive) & $40 / 8$ & $43 / 6$ & $41 / 8$ & 0.794 \\
\hline Venous invasion (negative/positive) & $38 / 10$ & $42 / 7$ & $38 / 11$ & 0.554 \\
\hline
\end{tabular}




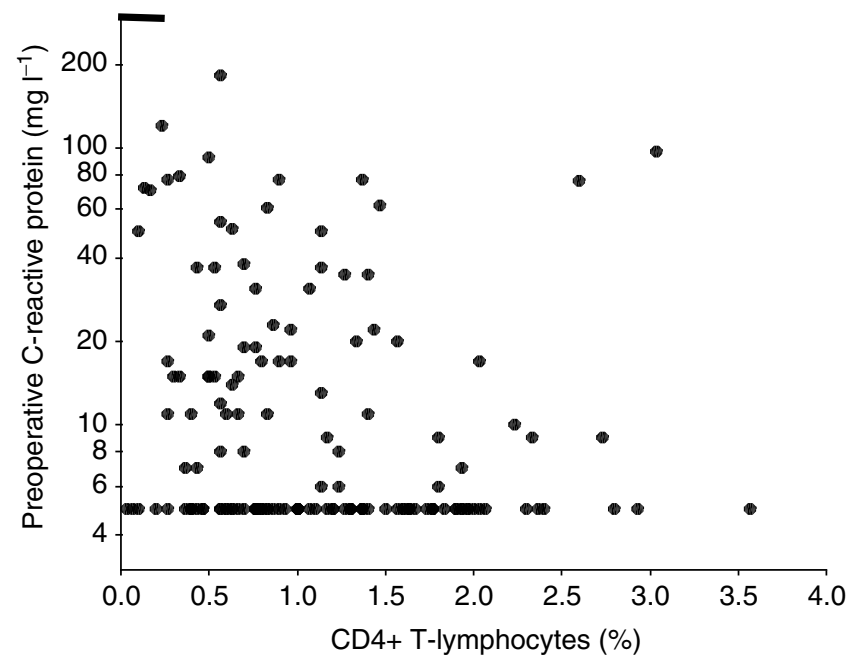

Figure I Relationship between percentage tumour CD4+ T-lymphocyte infiltration and preoperative C-reactive protein in patients undergoing potentially curative resection for colorectal cancer.

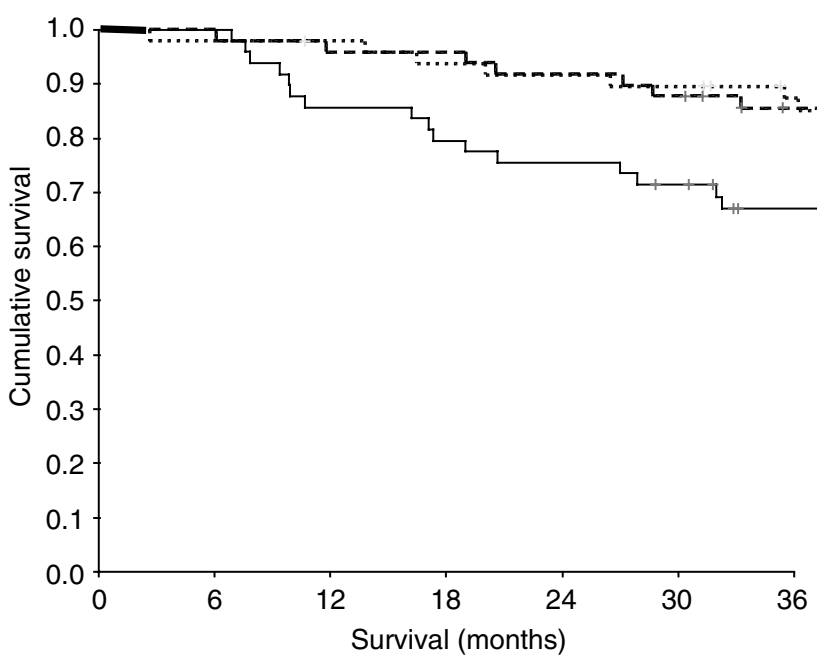

Figure 2 Relationship between tumour CD4 + T-lymphocyte infiltration (tertiles decreasing from top to bottom) and cancer-specific survival in patients undergoing potentially curative resection for colorectal cancer.

were similar in terms of age, sex, tumour site, stage and tumour characteristics. There was an inverse relationship between percentage tumour CD4 + T-lymphocytes and C-reactive protein $\left(r_{\mathrm{s}}=-0.245, P=0.003\right.$, Figure 1$)$. However, there was no relationship between percentage tumour CD8 + T-lymphocytes and Creactive protein $\left(r_{\mathrm{s}}=-0.091, P=0.273\right)$. There was a positive relationship between percentage tumour CD4 + and CD8 $+\mathrm{T}$ lymphocytes $\left(r_{\mathrm{s}}=0.440, P<0.001\right)$.

The minimum follow-up was 30 months; the median follow-up of the survivors was 62 months. During the course of the study, 55 patients died, 39 patients of their cancer and 16 of intercurrent disease. On univariate analysis, increased age $(P<0.001)$, sex $(P=0.052)$, Dukes' stage $(P<0.001)$ and venous invasion $(P=0.002)$ were associated with poorer cancer-specific survival. A decreased percentage tumour volume of $\mathrm{CD} 4+\mathrm{T}$-lymphocytes $(P=0.025$, Figure 2$)$ and an elevated $\mathrm{C}$-reactive protein $(P<0.001$, Figure 3 ) were also associated with poorer cancer-specific survival. However, the relationship between percentage tumour volume of

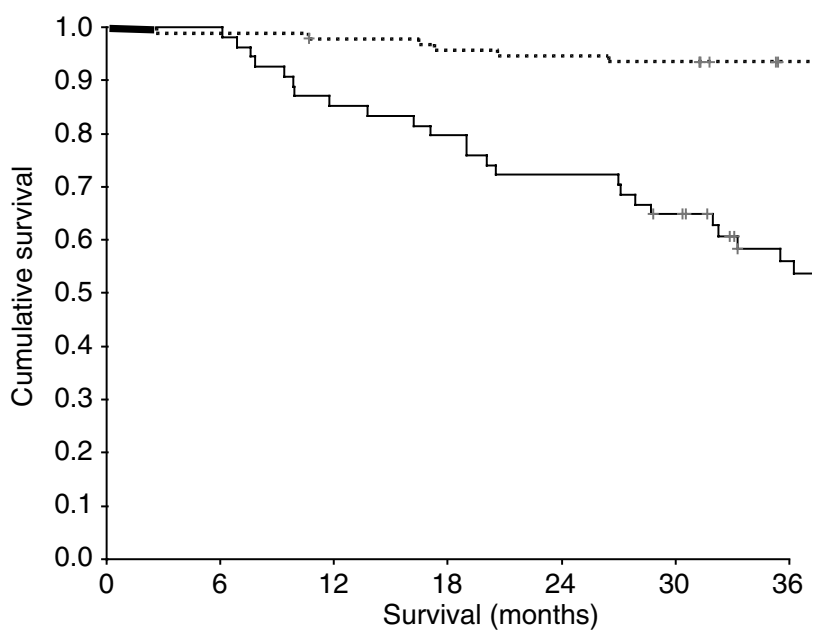

Figure 3 Relationship between preoperative C-reactive protein $(\leqslant 10 /$ $>10 \mathrm{mgl}^{-1}$ from top to bottom) and cancer-specific survival in patients undergoing potentially curative resection for colorectal cancer.

CD8 + T-lymphocytes and cancer-specific survival failed to reach statistical significance $(P=0.074)$.

On multivariate analysis, only age (HR 2.05, 95\% CI $1.30-3.23$, $P=0.002$ ), stage (HR 4.39, 95\% CI $2.14-9.00, P<0.001$ ) and Creactive protein (HR 4.66, 95\% CI 2.20-9.89, $P<0.001$ ) retained independent significance.

\section{DISCUSSION}

In the present study, a poor tumour CD4 + T-lymphocyte infiltrate was associated with an elevated circulating C-reactive protein concentration in patients undergoing potentially curative resection for colorectal cancer. Furthermore, both $\mathrm{CD} 4+\mathrm{T}$ lymphocytes and C-reactive protein were associated with a poor outcome. Therefore, the results of the present study indicate that both local and systemic inflammatory responses are linked and predict outcome independent of tumour stage.

These results appear to be consistent with previous work by Naito et al (1998), who showed that tumour CD8 + T-lymphocyte infiltrate had prognostic value in patients with colorectal cancer. However, they did not assess the tumour CD4 + T-lymphocyte infiltrate and used a less extensive sampling method. Furthermore, they included patients with Dukes' A tumours who were unlikely to progress and patients with Dukes' D tumours who had already progressed (Naito et al, 1998).

In the present study, tumour T-lymphocyte subset density was assessed using extensive sampling and a point counting technique. This approach provided an objective assessment of lymphocytic infiltration and circumvents the problem of variation in distribution of lymphocytes within an individual tumour. The present study was also confined to patients with Dukes' B and C tumours.

It was of interest that C-reactive protein (a systemic inflammatory response) was superior to tumour T-lymphocytic infiltration (a local inflammatory response) in predicting cancer specific survival. One possible explanation is that C-reactive protein can be measured with greater accuracy and precision than tumour T-lymphocytic infiltration. Alternatively, the systemic inflammatory response may be more important in determining survival in these patients.

The relationship between tumour CD4 + T-lymphocytic infiltration and cancer-specific survival is the opposite of that previously reported for both renal and prostate cancer (Bromwich et al, 2003; McArdle et al, 2004a). The reasons for this are as yet 
unclear. However, given that tumour lymphocytic infiltration parallels that of other inflammatory cells (Nielsen et al, 1999; Lin and Pollard, 2004) and that an elevated C-reactive protein is associated with poor outcome in all three tumours (Lewenhaupt et al, 1990; Blay et al, 1992; McMillan et al, 2003), it appears likely that the source of interleukin-6, the primary stimulus for the production of C-reactive protein, (Gabay and Kushner, 1999), differs in different tumours.

It is of interest therefore that McArdle et al (2004b) have recently reported that the relationship between interleukin- 6 and C-reactive protein was similar in benign prostatic hyperplasia and prostate cancer, and that there was no relationship between interleukin-6 and PSA concentrations. This would suggest that, in prostate cancer at least, interleukin-6 is produced by the inflammatory cells.

In colorectal cancer, it has been reported that interleukin-6 concentrations increase with tumour stage and correlate with CEA concentrations. This might therefore suggest that interleukin- 6 is produced by the tumour cells (Kinoshita et al, 1999; Belluco et al, 2000; Miki et al, 2004). If this were to prove to be the case, it would have important implications for the treatment of the systemic inflammatory response in patients with different tumours.

In the present study, we attempted to assess interleukin-6 within the tumour using different methods of antigen retrieval and staining and the use of negative and positive controls. However, we were unable to reliably identify regions of IL- 6 expression in the colorectal tumours due to deep background staining, which precluded accurate scoring of IL-6-positive cells in the tumour tissue.

In summary, the results of the present study show that, in patients undergoing curative resection for colorectal cancer, low tumour CD4 + T-lymphocyte infiltration is associated with elevated C-reactive protein concentrations. Furthermore, both a low tumour $\mathrm{CD} 4+\mathrm{T}$-lymphocyte infiltration and an elevated C-reactive protein predict poor cancer-specific survival.

\section{ACKNOWLEDGEMENTS}

We gratefully acknowledge the assistance of $\mathrm{Mr} \mathrm{JH}$ Anderson, and Mr P Horgan and the technical expertise of Mr D Murray.

\section{REFERENCES}

Ali AA, McMillan DC, Matalka II, McNicol AM, McArdle CS (2004) Tumour T-lymphocyte subset infiltration and tumour recurrence following curative resection for colorectal cancer. Eur J Surg Oncol 30: 292-295

Anderson JA, Dunnill MS (1965) Observations on the estimation of the quantity of emphysema in the lungs by the point-sampling method. Thorax 20: $462-466$

Belluco C, Nitti D, Frantz M, Toppan P, Basso D, Plebani M, Lise M, Jessup JM (2000) Interleukin-6 blood level is associated with circulating carcinoembryonic antigen and prognosis in patients with colorectal cancer. Ann Surg Oncol 7: 133-138

Blay JY, Negrier S, Combaret V, Attali S, Goillot E, Merrouche Y, Mercatello A, Ravault A, Tourani JM, Moskovtchenko JF (1992) Serum level of interleukin 6 as a prognosis factor in metastatic renal cell carcinoma. Cancer Res 52: 3317-3322

Bromwich EJ, McArdle PA, Canna K, McMillan DC, McNicol A-M, Brown M, Aitchison M (2003) The relationship between T-lymphocyte infiltration, stage, tumour grade and survival in patients undergoing curative surgery for renal cell cancer. Br J Cancer 89: 1906-1908

Dukes CE, Bussey HJR (1958) The spread of rectal cancer and its effect on prognosis. Br J Cancer 12: 309-320

Gabay C, Kushner I (1999) Acute-phase proteins and other systemic responses to inflammation. $N$ Engl J Med 340: $448-454$

Jass JR, Love SB, Northover JM (1987) A new prognostic classification of rectal cancer. Lancet 1(8545): $1303-1306$

Kinoshita T, Ito H, Miki C (1999) Serum interleukin-6 level reflects the tumor proliferative activity in patients with colorectal carcinoma. Cancer 85: $2526-2531$

Lewenhaupt A, Ekman P, Eneroth P, Nilsson B (1990) Tumour markers as prognostic aids in prostatic carcinoma. Br J Urol 66: $182-187$

Lin EY, Pollard JW (2004) Role of infiltrated leucocytes in tumour growth and spread. Br J Cancer 90: 2053-2058

McArdle PA, Canna K, McMillan DC, McNicol AM, Campbell R, Underwood MA (2004a) The relationship between T-lymphocyte subset infiltration and survival in patients with prostate cancer. $\mathrm{Br} J$ Cancer 91: $541-543$
McArdle PA, McMillan DC, Sattar N, Wallace AM, Underwood MA (2004b) The relationship between interleukin- 6 and C-reactive protein in patients with benign and malignant prostate disease. Br J Cancer 91: 1755-1757

McMillan DC, Canna K, McArdle CS (2003) Systemic inflammatory response predicts survival following curative resection of colorectal cancer. Br J Surg 90: 215-219

McMillan DC, Wotherspoon HA, Fearon KC, Sturgeon C, Cooke TG, McArdle CS (1995) A prospective study of tumor recurrence and the acute-phase response after apparently curative colorectal cancer surgery. Am J Surg 170: 319-322

Miki C, Konishi N, Ojima E, Hatada T, Inoue Y, Kusunoki M (2004) C-reactive protein as a prognostic variable that reflects uncontrolled up-regulation of the IL-1-IL-6 network system in colorectal carcinoma. Dig Dis Sci 49: 970 -976

Naito Y, Saito K, Shiiba K, Ohuchi A, Saiqenji K, Naqura H, Ohtani H (1998) CD8+ T cells infiltrated within cancer cell nests as prognostic factor in human colorectal cancer. Cancer Res 58: 3491 - 3494

Nielsen HJ, Christensen IJ, Sorensen S, Moesgaard F, Brunner N (2000) Preoperative plasma plasminogen activator inhibitor type-1 and serum C-reactive protein levels in patients with colorectal cancer. The RANX05 Colorectal Cancer Study Group. Ann Surg Oncol 7: 617-623

Nielsen HJ, Hansen U, Christensen IJ, Reimert CM, Brunner N, Moesgaard F, The RANX05 Study Group (1999) Independent prognostic value of eosinophil and mast cell infiltration in colorectal cancer tissue. J Pathol 189: $487-495$

O'Byrne KJ, Dalgleish AG (2001) Chronic immune activation and inflammation as the cause of malignancy. Br J Cancer 85: 473-483

O'Gorman P, McMillan DC, McArdle CS (2000) Prognostic factors in advanced gastrointestinal cancer patients with weight loss. Nutr Cancer 37: $36-40$

Ropponen KM, Eskelinen MJ, Lipponen PK, Alhava PK, Kosma VM (1997) Prognostic value of tumour-infiltrating lymphocytes (TILs) in colorectal cancer. J Pathol 182: 318-324

Vakkila J, Lotze MT (2004) Inflammation and necrosis promote tumour growth. Nat Rev Immunol 4: 641-648 